\title{
REFLEXÕES SOBRE O ENSINO DE DINÂMICA DE GRUPO PARA ALUNOS DE GRADUAÇÃO EM ENFERMAGEM ${ }^{1}$
}

\section{REFLECTIONS ABOUT THE UNDERGRADUATE NURSING TEACHING ON GROUP DYNAMICS.}

\author{
Toyoko Saeki* \\ Denize Bouttelet Munari* * \\ Marcia Bucchi Alencastre* \\ Maria Conceição B. M. Souza***
}

SAEKI, T. Reflexões sobre o ensino de dinâmica de grupo para alunos de graduação em enfermagem. Rev. Esc. Enf. USP., v. 33, n. 4, p. 342-7, dez. 1999.

\section{7.}

Este artigo resgata, descreve e remete a uma reflexão sobre nossa experiência com o ensino de dinamica de grupos para graduandos de enfermagem, iniciada em 1992 . Focaliza a questão da enfermagem e o trabalho com grupos; a estrutura, conteúdo e desenvolvimento da disciplina.

UNITERMOS: Enfermagem. Ensino. Dinâmica de grupos.

\section{Thin}

The present article aims at reflecting on the experience of the authors about the nursing undergraduate teaching on group dynamics, that began in 1992. Authors focus nursing and the works with groups; the structure, content and development of this specific course.

UNITERMS : Nursing. Teaching. Group dynamics.

\section{INTRODUÇÃO}

Pensar a educação e o ensino na atualidade é um desafio para todo professor e, a prática docente na Universidade, não fica à margem dessa questão.

Enquanto docentes de Enfermagem na área de Saúde Mental, estamos a todo momento refletindo sobre nossa prática, focalizando nossa tarefa sobretudo na formação da competência humana. Entendemos que esse é nosso papel na formação do enfermeiro, pois, não tratamos de trabalhar com o conhecimento técnico isoladamente, mas articulado ao desenvolvimento dos recursos internos do aluno como ser humano.

Pensando desta maneira, é necessário permitir ao aluno trazer sua "história" para a situação de aprendizado, para que o conteúdo a ser aprendido tenha realmente significado para ele.

Para JAPUR; LOUREIRO; CAMPOS e MUNARI (1992), esta forma de aprendizagem tem sido valorizado por muitos professores por esses reconhecerem $a$ importância do desenvolvimento pessoal do aluno, sobretudo na formação daqueles profissionais que têm a própria interação humana, seja interpessoal ou grupal, como o recurso essencial à sua atuação profissional. (p. 52).

Acreditamos que o indivíduo estimulado a aprender dentro desta perspectiva consegue apreender a realidade, transformá-la e, finalmente, compreender

1 Trabalho apresentado no VI Colóquio Pan-Americano de Investigação em Enfermagem, Ribeirão Preto, de 19 a 22 de maioe 1998.

* Enfermeira. Professor Doutor do Departamento de Enfermagem Psiquiátrica e Ciências Humanas da Escola de Enfermagem de Ribeirão Preto - USP. e-mail: maryto@glete.eerp.usp.br

* Enfermeira. Professor Titular da Faculdade de Enfermagem da Universidade Federal de Goiás. e-mail:mdrph@internetional.com.br

*.* Enfermeira. Professor Assistente do Departamento de Enfermagem Psiquiátrica e Ciências Humanas da Escola de Enfermagem de Ribeirão Preto - USP 
que sua ação consciente e competente no ambiente social é fundamental para o desenvolvimento de uma sociedade melhor e mais justa.

Trabalhar dentro dessa visão de mundo não é coisa muito fácil, porém certamente desenvolve no indivíduo a sua caracterização como um ser social, que dá atenção às suas relações com o mundo em que vive. Segundo DILLY ; JESUS (1995) ,é na relação com os outros homens que se adquire os meios que possibilitam o existir humano.(p.20)

É ainda dentro dessa perspectiva que pensamos o nosso papel de "professor/aprendiz", que pode renovar sua ação cotidianamente e considerar 0 aprendizado e o desenvolvimento do aluno um êxito seu também..

Parar para elaborar esta reflexão remeteu-nos a retomar nossas idéias iniciais, reformulá-las, reestruturá-las e torná-las mais claras aos nossos olhos. É sem dúvida alguma, um exercício necessário aos professores que não se sentem donos do saber, mas partícipes junto de seus alunos na construção de profissionais mais amadurecidos e responsáveis.

\section{A ENFERMAGEM E O TRABALHO COM GRUPOS}

A tendência mundial na realização de atividades em grupo, acrescida da própria característica do homem em estabelecer-se como um ser gregário, faz com que pensemos de que forma, nós enfermeiros, temos nos posicionado frente às experiências de vivenciar os grupos.

A relevância do estudo da dinâmica grupal é apontada por OSÓRIO (1986), como um fato que sinaliza a necessidade do ser humano em buscar compreender os movimentos presentes no interior dos grupos, de forma a contribuir para o aperfeiçoamento e melhoria das sociedades humanas.

No nosso entendimento, perceber esses movimentos possibilita-nos apreender nossos limites e possibilidades de atuação dentro dos grupos para que possamos usufruir dessas experiências de forma ativa. Isso significa dizer que se é possível "viver" o grupo é também possível dar, receber e trocar idéias e sentimentos.

Viver o grupo significa ainda lidar com a diversidade, com a falta de algo pronto e acabado, com a possibilidade do conflito e do confronto, mas também, com a união e a criação.

As atividades grupais realizadas pelos enfermeiros compreendem desde as tarefas desenvolvidas pela equipe de enfermagem, as orientações feitas a um grupo de pessoas que necessitem de suporte emocional, ou que estejam aprendendo a adaptar-se às novas situações de vida (MUNARI, 1995).
O mesmo estudo citado anteriormente revela ainda que, desde a década de setenta, a produção científica dos enfermeiros brasileiros sobre essa temática vem aumentando quantitativa e qualitativamente, especialmente nos últimos anos.

No entanto, o que observamos em levantamentos bibliográficos realizados em periódicos nacionais sobre esse tema, é que poucos trabalhos deixam explícitos os elementos que fundamentam as atividades desenvolvidas. A maioria detém-se na apresentação das experiências vivenciadas.

Este fato se dá uma vez que muitos enfermeiros desenvolvem suas atividades de modo empírico, ou seja, aprendendo a fazer com a própria experiência, dado esse constatado por MUNARI (1995).

Dependendo do objetivo que.se pretende com a utilização do grupo como estratégia (socialização, mudança de comportamento, treino de relações humanas ou ainda a psicoterapia), vários aspectos deverão ser considerados. Destacamos fundamentalmente o preparo do enfermeiro para a realização dessa tarefa. $O$ profissional deve estar ciente daquilo que poderá encontrar, conhecer os movimentos grupais e as formas mais comuns de manejo. Vale lembrar ainda que para aqueles grupos onde está implícito o objetivo psicoterápico, o enfermeiro deve, obrigatoriamente, estar fundamentado por uma formação específica.

Isso não exclui a importância da formação dos enfermeiros que trabalham com outros tipos de grupos, uma vez que a situação grupal, independente do seu objetivo pode mobilizar sentimentos, emoções e comportamentos cujo manejo pode apresentar dificuldade ao coordenador.

Os profissionais que ignoram, ou que não dão a essa questão a devida relevância, podem correr riscos, abordando inadequadamente várias situações grupais.

Consideramos como parte dessa formação do enfermeiro a auto-reflexão, para que como coordenador o profissional se perceba como um elemento do grupo e hẩo um "chefe" que anda à margem dele. Segundo MUNARI ; RODRIGUES (1997), a caractertstica essencial daquele que coordena está justamente em contar com suas experiências como sujeito de um grupo, com suas vivências pessoais em atividades grupais, que lhe sirvam de espelho para o auto-conhecimento e uma visão critica de si mesmo e do seu papel nos grupos sociais.(p.93)

É justamente fundamentadas nos pressupostos que esboçamos até o momento que apresentamos nossa preocupação, enquanto professores da área de Enfermagem Psiquiátrica e Saúde Mental em buscar instrumentalizar os futuros enfermeiros para o desempenho dos trabalhos com grupos, almejando pelo menos despertá-los para a questão. 
O propósito deste trabalho é descrever uma reflexão sobre o ensino da dinâmica de grupo para estudantes de graduação em Enfermagem, focalizando a sua relevância para a formação do enfermeiro.

\section{A DISCIPLINA}

Os estudos para a reforma curricular da Escola de Enfermagem de Ribeirão Preto da Universidade de São Paulo (EERP-USP) tiveram início em 1979 e culminaram com a implantação de um novo currículo em 1989. Neste processo pretendia-se uma mudança global do currículo a partir da discussão de um marco referencial, tendo como base as necessidades de saúde da população, propostas governamentais para a área da saúde e o próprio desenvolvimento da Enfermagem enquanto uma prática social (FREITAS; TAVARES; SAEKI, 1985).

Na nova grade curricular, as disciplinas da área de Enfermagem Psiquiátrica do Departamento de Enfermagem Psiquiátrica e Ciências Humanas sofreram algumas alterações com a inclusão da disciplina Dinâmica das Relações em Grupo na Enfermagem.

A introdução desta disciplina no currículo foi decorrente de discussões junto aos alunos e docentes cujas opiniões sobre a mesma destacavam a relevância desse conteúdo na formação pessoal e profissional do enfermeiro.

Em 1992, seu primeiro ano de oferecimento, ela ocorria no oitavo semestre concomitantemente com as disciplinas: Estudos de Problemas Brasileiros, Administração de Enfermagem em Unidade de Saúde Pública e Administração Aplicada à Enfermagem Hospitalar.

No ano seguinte, devido a concentração da carga horária didática das disciplinas da área de Enfermagem Psiquiátrica ministradas no segundo semestre de cada ano - Enfermagem Psiquiátrica Preventiva ( $75 \mathrm{Hs}$ ), Enfermagem Psiquiátrica $(180 \mathrm{Hs})$ e Dinâmica das Relações em Grupo na Enfermagem ( $60 \mathrm{Hs}$ ) - essa última foi transferida para o sétimo semestre, onde permanece.

Nesse semestre, ela acompanha Enfermagem Pediátrica, Enfermagem Obstétrica e Ginecológica, Ética e Legislação em Enfermagem, Didática II, Psicologia II e Estudos dos Problemas Brasileiros II. Com exceção desta última, as demais continuam compondo o sétimo semestre.

Ao longo desses cinco anos, a disciplina vem sendo desenvolvida em 60 horas distribuídas em 15 semanas, em um período de quatro horas por semana e tem como objetivo propiciar ao aluno a compreensão de aspectos da dinâmica das relações interpessoais em grupo no desempenho de suas atividades enquanto profissional de enfermagem.
Quanto aos objetivos específicos, visa ensinar o estudante sobre as origens e evolução dos grupos; oferecer noções básicas sobre as fases de desenvolvimento dos grupos; propor elementos de reflexão sobre a coordenação de grupos e possibilitar a discussão das relações em grupo observadas nas experiências de trabalho.

Para o desenvolvimento da disciplina com uma proposta teórico - vivencial, dividimos os alunos em três subgrupos coordenados por três docentes, que procuram trabalhar integrados para manter a unidade da mesma.

O conteúdo teórico enfoca noçães sobre a origem, evolução e aspectos conceituais de grupos; fases de desenvolvimento dos grupos; o indivíduo e o grupo; comunicação humana nos grupos; interações e participação nos grupos; o grupo e sua repercussão no trabalho da Enfermagem e a prática dos enfermeiros com o trabalho grupal.

Esse conteúdo está alicerçado em referências sobre dinâmica de grupos e textos de experiências de atividades grupais realizadas pela Enfermagem. Encontram-se discriminadas em anexo (Anexo 1).

Através dos temas selecionados esperamos que os mesmos sirvam de base para que o aluno possa refletir sobre suas vivências em sala de aula e também aquelas oriundas dos campos de estágio junto às disciplinas que são desenvolvidas paralelamente.

Além das estratégias tais como: leituras programadas, estudos dirigidos, discussões em grupo, utilizamos vivências e jogos dramáticos que possibilitam reflexões relacionadas aos aspectos teóricos estudados.

Cada aula é programada em dois momentos onde estão previstos debates de textos previamente estudados e vivências que envolvem música, atividades físicas e recreativas, exercícios práticos de dinâmica de grupo e de relações humanas, dramatizações, apresentações artísticas como jograis, peças teatrais, conjuntos musicais, danças, entre outras, pertinentes ao assunto a ser explorado no dia.

Essas atividades são realizadas, em sua maioria, em grupos de até 25 alunos coordenados por um docente, sendo que em algumas ocasióes estão previstos encontros onde são reunidos todos os alunos, chegando a mais de 70 participantes.

A forma como está elaborada a disciplina proporciona aos estudantes um espaço aberto para críticas e sugestões das tarefas, bem como a utilização da experiência como reflexão sobre as vicissitudes do trabalho grupal, ou seja, os participantes podem experienciar a dinâmica de um grupo, que é o enfoque central da disciplina.

Para cada encontro com os alunos, os docentes se preparam lendo e discutindo antecipadamente os textos selecionados. Reúnem-se antes de entrarem nas salas de aula para rever a programação e acertar detalhes. 
Após o término das atividades com os estudantes, os professores voltam a se reunir para relatar a experiência de cada subgrupo e reorientar os próximos encontros.

Consideramos essa integração essencial para o caminhar harmônico dos subgrupos, no entanto, acreditamos que cada um deles tenha um desenvolvimento próprio e que questões e situações que emergirem podem e devem ser trabalhadas no momento e no contexto dos pequenos grupos.

Nos primeiros anos pudemos contar com a colaboração de um ator e diretor de teatro que, durante as vivências, desenvolvia com os estudantes e docentes uma oficina de teatro que possibilitava a articulação com os aspectos teóricos. A originalidade e ousadia dessa proposta enriqueceu a disciplina, trabalhando sobremaneira a criatividade e espontaneidade dos alunos e preparando melhor os docentes para o manejo de grandes grupos.

Os estudantes são avaliados através da participação, contribuição nas discussões, compromisso com o grupo e freqüência às aulas, apresentação dos trabalhos propostos e uma reflexão por escrito, que consta basicamente de itens sobre o conteúdo teórico - vivencial do curso e o significado da disciplina para eles.

Nos primeiros dois anos essa reflexão era individual. Depois os professores e alunos decidiram que seria mais oportuna sua elaboração em pequenos grupos. É ainda solicitada para cada estudante, por escrito, uma auto - avaliação onde faz uma análise de seu desempenho, atribuindo-se uma nota e justificando a mesma.

Ao término da disciplina pedimos aos alunos para procederem uma avaliação da mesma, focalizando seus objetivos, conteúdo, estratégias metodológicas, relacionamento professor(es) - aluno(s), formas de avaliação e referências bibliográficas.

\section{REVISITANDO A EXPERIÊNCIA}

Acreditamos que toda a experiência vivenciada por nós nestes anos permite-nos algumas considerações importantes sobre o ensino da dinâmica de grupos para estudantes de graduação em Enfermagem.

Um aspecto fundamental trabalhado em todo o percurso da disciplina é a oportunidade de discutir junto com 0 aluno as dificuldades e as possibilidades concretas da realização do trabalho coletivo. Assim é possível viver as diferenças e divergências sem que isso signifique ruptura ou desagregação, pois de acordo com MAILIHOT (1981) o ser humano, qualquer que seja seu grau de socialização, deve libertar-se desta falsa obsessão de que só aqueles que nos parecem semelhantes nos são próximos e que para serem fraternais conosco, os outros devem ser idênticos a nós.(p.88).
Além disso consideramos que o conflito e o confronto são necessários para que os alunos desenvolvam flexibilidade e consenso, atitudes não muito fáceis de serem adquiridas.

Em relação ao conteúdo térico pensamos que atende aos objetivos da disciplina e está alicerçado em um referencial bibliográfico que vem sendo constantemente revisado, uma vez que ele deve ser adequado ao aluno de graduação e às especificidades das situações grupais que se apresentam na área da saúde.

A carga horária nos parece suficiente para a ministração do conteúdo e permite o acompanhamento dos estudantes durante todo o semestre.

Ressaltamos que a utilização da abordagem teórico - vivencial como estratégia de condução da disciplina é fundamental para o seu desenvolvimento. Para JAPUR; LOUREIRO; CAMPOS e MUNARI (1992), os programas acadêmicos de formação de profissionais não têm valorizado devidamente essas experiências, pois o planejamento do ensino na Universidade é voltado para a valorização do conhecimento técnico - científico.

As mesmas autoras destacam que ao considerar apenas essa dimensão, do técnico -cientifico, deixa-se de valorizar o processo de aprendizagem significativa definida por Moreno apud JAPUR; LOUREIRO; CAMPOS e MUNARI (1992) como uma assimilação a mim mesmo daquilo que aprendo, em contraposição a uma mera assimilação de conhecimentos $e$ informações sem nenhuma conexão comigo (p.52).

Vale salientar a importância da colaboração de outros profissionais - de teatro, educação física, terapeutas ocupacionais e recreacionais - que são parceiros favoráveis para esse tipo de trabalho no sentido de nos auxiliar a repensar e elaborar novas propostas.

A motivação ao começarmos a construir esta disciplina veio do desafio de educarmos saindo da situação comum de sala de aula. Pensamos que isso só foi possível pelas características pessoais e profissionais dos docentes envolvidos.

Nosso preparo, além de contemplar uma formação extensa em Enfermagem Psiquiátrica e Saúde Mental, inclui cursos de dinâmica de grupos, experiências com psicodrama e vivências psicoterápicas individuais e/ou em grupos.

Salientamos a necessidade desse preparo porque os professores/coordenadores precisam ter uma postura humana de respeito ao outro, aceitação e flexibilidade. Além disso, o docente deve ter um conhecimento de si mesmo para que possa saber de suas limitações e enfrentar as dificuldades que surjam nas relações. $\dot{E}$ preciso que tenhamos consciência e que possamos viver o papel de facilitadores de um processo de desenvolvimento de pessoas, inclusive o nosso próprio e que para isso é necessário que haja clima e espaço 
para a emergência de potencialidades criativas. (MUNARI; RODRIGUES,1997, p.92)

Nesse sentido, o enriquecedor da disciplina é a possibilidade de estar constantemente se vendo através dos olhos dos alunos e dos outros colegas.

Para um bom desenvolvimento da disciplina acreditamos ser preciso muita organização, envolvimento, sincronia, compromisso e determinação entre os docentes. Tudo é pensado, repensado e um contrato de trabalho é firmado entre os professores e alunos.

A proposta da disciplina é apresentada e discutida na primeira aula nos subgrupos e as modificações e sugestões que aparecem durante sua trajetória são sempre elaboradas com a participação de todos. Acreditamos estar a todo momento compartilhando a construção do aprendizado, considerando a contribuição de cada aluno, compreendendo-o como ser histórico e sujeito do seu próprio movimento.

Percebemos que quando a proposta de ensino para o estudante não é dada de forma tradicional, formal, fechada, cria-se a possibilidade para ele parar e pensar e não meramente reproduzir conhecimentos e comportamentos que lhe são passados (DEMO, 1996; FREIRE, 1987).

Nos primeiros encontros observamos que os alunos sentem alguma dificuldade para compreender a dinâmica da disciplina uma vez que para eles, geralmente habituados a receber as informações e pouco participar do seu processo de aprendizado, também fica difícil sair de seu papel tradicional.

Com o passar do tempo, na medida em que os subgrupos se constituem como tal, observa-se um certo amadurecimento. Eles tornam-se mais participativos e comprometidos com o andamento daqueles e da própria disciplina.

É importante pontuar, no entanto, que alguns deles conseguem pensar e agir de maneira mais coletiva enquanto que outros parecem entrar e sair da disciplina sem que possamos perceber neles quaisquer mudanças. Isso nos leva a considerar que a disponibilidade interna de cada participante do grupo difere em intensidade e significado atribuído à atividade.

Finalizamos reafirmando a importância da revisão permanente do caminhar da disciplina durante todo o semestre, contando com a contribuição dos alunos, que sempre nos dão o feedback para nortear nossas ações .E registrando que essa experiência tem sido gratificante e nos possibilitado muitas oportunidades de amadurecimento.

\section{REFERÊNCIAS BIBLIOGRÁFICAS}

DEMO, P. Educar pela pesquisa. Campinas, Autores Associados, 1996.

DILLY, C. M. L. ; JESUS, M. C. P. Processo educativo em enfermagem: das concepções pedagógicas à prática profissional. São Paulo, Robe Editorial, 1995.

FREIRE, P. Pedagogia do oprimido. Rio de Janeiro, Paz e Terra, 1987.

FREITAS, D. M. V.; TAVARES, M. S. G.; SAEKI, T. O ensino de graduação em enfermagem da Escola de Enfermagem de Ribeirão Preto - USP. In FREITAS, D. M. V. et al. Livro Comemorativo do $30^{\circ}$ aniversário da Escola de Enfermagem de Ribeirão Preto da Universidade de São Paulo. Ribeirão Preto, 1985. p. 44-61.

JAPUR, M.; LOUREIRO, S. R.; CAMPOS, M. A.; MUNARI, D. B. A aprendizagem teórico-vivencial: exploração de alguns limites e possibilidades. Paidéia. v.2, p.51-60, 1992.

MAILHIOT, G. B. Dinâmica e gênese dos grupos. São Paulo, Duas Cidades, 1981.

MUNARI, D. B. Processo grupal em enfermagem: possibilidades e limites. Ribeirão Preto, 1995. 130p. Tese (Doutorado)- Escola de Enfermagem de Ribeirão Preto, Universidade de São Paulo.

MUNARI, D.B.; RODRIGUES ,A.R.F. Enfermagem e grupos. Goiânia, AB Editora, 1997.

OSÓRIO, L. C. et al. Grupoterapia hoje. Porto alegre, Artes Médicas, 1986.

\section{Anexo 1}

\section{Referências Bibliográficas da disciplina Dinâ- mica das Relações em Grupo na Enfermagem}

ATKINSON, L. D.; MURRAY, M. E. Fundamentos de enfermagem: introdução ao processo de enfermagem . Rio de Janeiro, Guanabara Koogan , 1989.

AUBRY, J.M.; ARNAUD, Y.S. Dinâmica de grupo. São Paulo, Loyola, 1978

BEAL, G, M.; BOHLEN, J. M; RAUDABAUGH, J. N. Liderança e dinâmica de grupo. Rio de Janeiro, Zahar, 1970.

BLAYA, M. Grupos operativos hospitalares. Trabalho apresentado no $\mathrm{V}$ congresso Latino Americano de Psicoterapia de Grupo . São Paulo, 1967.

CAMPOS, M. A. Experiência de trabalho em uma equipe multi - disciplinar de um hospital dia psiquiátrico universitárioreflexões sobre dinâmica de grupo. Rev. ABPAPAL, v. 30, n. 10, p. $30-4,1998$.

CAMPOS, M. A. O trabalho em equipe multiprofissional: uma reflexão crítica. Revista de Psiquiatria do Rio Janeiro./ No prelo/ 
CARTWRIGHT, D.; ZANDER, A. Dinâmica de grupo: pesquisa e teoria. São Paulo, EPU /EDUSP, 1975. v. 1.

Dibella, G. A. W. et al. Handbook of partial hospitalization. New York, Brunner/Mazel, 1982.

HENFIL. Diário de um cucaracha. Rio de Janeiro, Record, 1993.

MAILhIOT, G. B. Dinâmica e gênese dos grupos. São Paulo, 1977.

MINICUCCI, A. Dinâmica de grupo: teorias e sistemas. São Paulo, Atlas, 1987.

MOSCOVICI, F. Desenvolvimento interpessoal. Rio de Janeiro, LTC- Livros Técnicos e Científicos, 1985.
OLMSTED, M. S. O pequeno grupo social. São Paulo, EDUSP, 1970 .

OSÓRIO, L.C. et al. Grupoterapia hoje. Porto Alegre, Artes Médicas, 1986.

RIBEIRO, J.P. Psicoterapia grupo - analítica. Petrópolis, Vozes, 1981

SCHUTZ, W.C. Psicoterapia pelo encontro. São Paulo, Atlas, 1978.

WEIL,P.et al. Dinâmica de Grupo e desenvolvimento em relações humanas. Belo Horizonte, Itatiaia, 1967.

ZIMERMAN, D. E. Fundamentos básicos das grupoterapias. Porto Alegre, Artes médicas, 1993. 